\title{
Nhà khoa học Việt Nam trở thành thành viên Ban điêu hành của Hiệp hội Học thuật Quản trị Kinh doanh quốc tế
}

\author{
Hồng Liên
}

June 27, 2019

Dân Trí

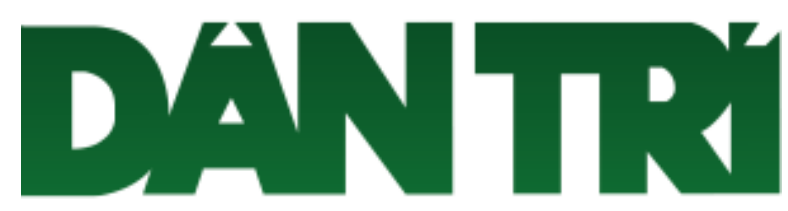

https://dantri.com.vn/giao-duc-huong-nghiep/nha-khoa-hoc-viet-nam-tro-thanh-thanhvien-ban-dieu-hanh-cua-hiep-hoi-hoc-thuat-quan-tri-kinh-doanh-quoc-te20190627135356902.htm 


\section{Nhà khoa học Việt Nam trở thành thành viên Ban điều hành của Hiệp hội Học thuật Quản trị Kinh doanh quốc tế}

(Dân trí) - Ngày 24/6/2019, TS. Vuơng Quân Hoàng, Giám đốc Trung tâm Nghiên cưu Xã hội Liên ngành (ISR), Truờng Đại học PHENIKAA đã được lựa chọn là thành viên Ban điều hành của Hiệp hội Học thuật Quản trị Kinh doanh quốc tế - Phân hội Đông Nam Á (Academy of International Business, Southeast Asia Regional Chapter - AIB$S E A R)$.

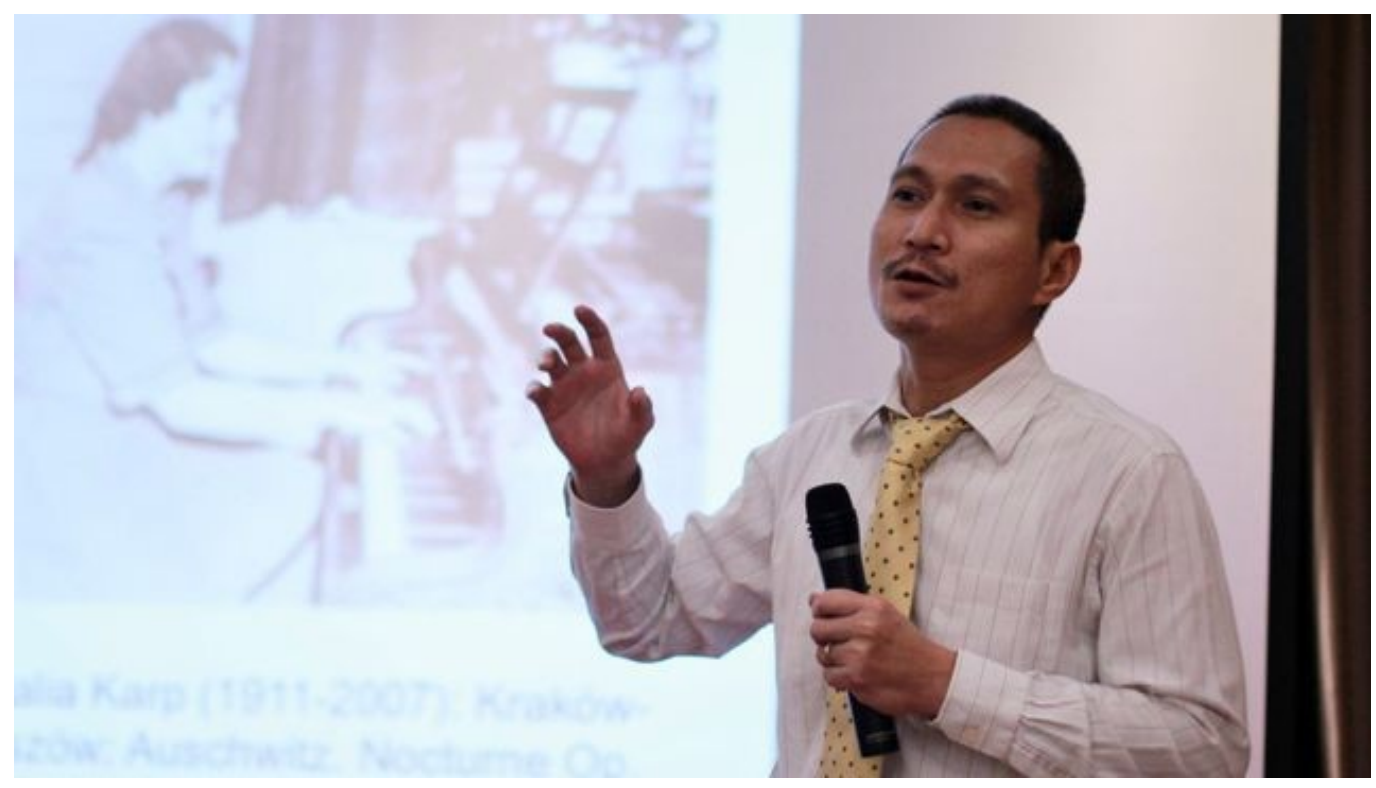

Là thành viên của AIB-SEAR, TS. Vuơng Quân Hoàng mong muốn đóng góp tiếng nói, quan điểm của Việt Nam tới bạn bè quốc tế.

Cùng trong vai trò thành viên Ban điều hành AIB-SEAR với hai nhà khoa học khác đến từ Singapore và New Zealand, TS. Vương Quân Hoàng có trách nhiệm cùng các thành viên khác cố vấn Ban Điều hành về định hướng phát triển của Phân hội, tham gia nghiên cứu, chia sẻ quan điểm về các vấn đề kinh tế, kinh doanh quốc tế tại các hội nghị thường niên của Hiệp hội. Thông qua hội nghị và tọa đàm với các thành viên AIB-SEAR, TS. Vương Quân Hoàng mong muốn đóng góp tiếng nói, quan điểm của Việt Nam tới bạn bè quốc tế.
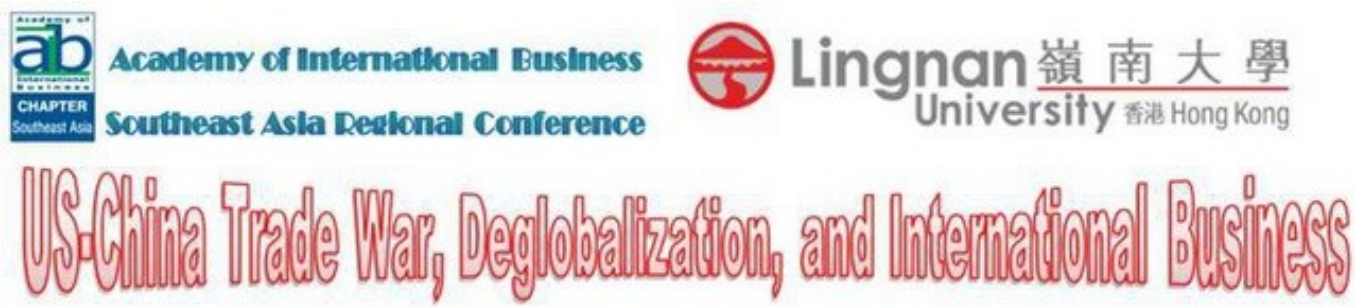

\section{Cebu, Philippines, 5 - 7 December 2019}

Hội nghị AIB-SEAR 2019 sẽ diễn ra tù ngày 5-7 tháng 12 năm 2019 tại Cebu, Philippines. TS. Vương Quân Hoàng tốt nghiệp tiến sĩ ngành Kinh tế tại Trường Đại học Tổng hợp Bruxelles, Vương quốc Bỉ. Trước khi trở thành Giám đốc Trung tâm Nghiên cứu Xã hội Liên ngành (ISR) thuộc Trường Đại học PHENKIKAA, TS. Hoàng đã có nhiều năm công tác tại nhiều đại học uy tín trong và ngoài nước. Đến nay, TS. Hoàng đã có gần 100 bài báo công bố trên các tạp chí quốc tế thuộc danh mục ISI, Scopus và 
PubMed, cũng như chương sách của các nhà xuất bản uy tín như Palgrave Macmillan, ABC Clio/Praeger, Routledge, World Scientific.

Trong năm 2018, TS. Vương Quân Hoàng đã có bốn công trình nổi bật được công bố trên các tạp chí hàng đầu thuộc hệ thống xuất bản Nature Research danh tiếng: Bài viết quan điểm về chi phí khoa học, đầu tư và làm khoa học hiệu quả tại các nền kinh tế đang phát triển Nature Human Behaviour [Chỉ số ảnh hưởng (JIF) năm $2018=$ 10.575]; Bài viết mô tả quá trình thiết kế, xây dựng, cấu trúc logic và hoạt động của cơ sở dữ liệu (CSDL) mở về năng suất của KHXH\&NV Việt Nam -SSHPA (http://sshpa.com/) trên Scientific Data [2018 JIF = 5.929]; Nghiên cứu sâu về sự nhạy cảm chi phí của người sử dụng dịch vụ y tế trên Palgrave Communications [2018 CiteScore $=0.88$ ]; và Nghiên cứu áp dụng phương pháp thống kê Bayesian để tìm hiểu về cộng tính văn hóa, với dữ liệu từ truyện cổ tích, dân gian Việt Nam cũng trên tạp chí Palgrave Communications.

Trong năm 2019, TS. Vương Quân Hoàng cùng kĩ sư Lã Việt Phương (Trung tâm ISR, Trường Đại học Phenikaa) xuất bản chương trình máy tính về thống kê BayesianBayesvl trên thư viện chính thức của $\mathrm{R}$ là $\mathrm{CRAN}$. Phần mềm Bayesvl được xây dựng hướng đến mục tiêu sư phạm, hỗ trợ người tiếp cận và sử dụng thống kê Bayesian thông qua xây dựng, thiết kế mô hình lưới Bayesian từ dữ liệu, tiến hành mô phỏng $\mathrm{MCMC}$, thực hiện kiểm tra thông số kĩ thuật và kết quả bằng hình ảnh.

Thành lập năm 1959, Hiệp hội Học thuật Quản trị kinh doanh Quốc tế (Academy of International Business - AIB) (https://aib.msu.edu/) là tổ chức học thuật quốc tế rất uy tín với 3.581 thành viên đến từ 96 quốc gia trên thế giới. Hiệp hội có 17 Phân hội của từng khu vực khác nhau trên thế giới. AIB là cơ quan xuất bản tạp chí hàn lâm lừng danh trong kinh tế - quản trị là Journal of International Business Studies, có 2018 Journal Impact Factor = 7.724, cao bậc nhất ngành kinh tế-quản trị (theo JCR 2019).

Phân hội Đông Nam Á trực thuộc AIB (Southeast Asia Regional Chapter (AIB-SEAR) (https://aib.msu.edu/community/chapters /CH_SoutheastAsia.asp) thành lập năm 1984. Phân hội bao gồm các quốc gia và vùng lãnh thổ: Bangladesh, Bhutan, Brunei, Campuchia, Guam, Hong Kong (SAR-PRC), Indonesia, Lào, Macau, Malaysia, Maldives, Myanmar, North Mariana Islands, Palau, Philippines, Singapore, Sri Lanka, Đài Loan, Thái Lan, Timor-Leste, Việt Nam.

Theo quy định của AIB-SEAR, một nhà khoa học đủ tiêu chuẩn trở thành thành viên Ban Điều hành cần được ba giáo sư tên tuổi giới thiệu với AIBSEAR. Từ cơ sở đó, Ban Điều hành bắt đầu xét duyệt hồ sơ và bầu chọn. Được các nhà khoa học hàng đầu tiến cử và bầu chọn vào một vị trí trong Ban Điều hành AIB-SEAR là một sự công nhận quý giá về phẩm chất, uy tín học thuật đối với mỗi nhà khoa học. Hội nghị năm 2019 của AIB-SEAR sẽ diễn ra từ ngày 5-7 tháng 12 năm 2019 tại Cebu, Philippines.

\section{Hồng Liên}

Link nội dung: https://dantri.com.vn/giao-duc-huong-nghiep/nha-khoa-hoc-viet-namtro-thanh-thanh-vien-ban-dieu-hanh-cua-hiep-hoi-hoc-thuat-quan-tri-kinh-doanh-quocte-20190627135356902.htm 


\section{Tài liệu tham khảo:}

Vuong, Q. H. (2018). The (ir) rational consideration of the cost of science in transition economies. Nature Human Behaviour, 2(1), 5.

Vuong, Q. H., Ho, T. M., Nguyen, H. K., \& Vuong, T. T. (2018). Healthcare consumers' sensitivity to costs: A reflection on behavioural economics from an emerging market. Palgrave Communications, 4(1), 70.

Vuong, Q. H., Bui, Q. K., La, V. P., Vuong, T. T., et al. (2018). Cultural additivity: behavioural insights from the interaction of Confucianism, Buddhism and Taoism in folktales. Palgrave Communications, 4(1), 143.

Vuong, Q. H., La, V. P., Vuong, T. T., Ho, M. T., et al. (2018). An open database of productivity in Vietnam's social sciences and humanities for public use. Scientific Data, 5(1), 180188.

La, V. P., \& Vuong, Q. H. (2019). bayesvl: Visually Learning the Graphical Structure of Bayesian Networks and Performing MCMC with 'Stan'. The Comprehensive R Archive Network (CRAN). Retrieved from: https://cran.rproject.org/web/packages/bayesvl/index.html 